\title{
Ethanol aversion induced by parenterally administered ethanol acting both as CS and UCS
}

\author{
DOM MICELI, PIERRETTE MARFAING-JALLAT, and JACQUES Le MAGNEN \\ Laboratoire de Neurophysiologie Sensorielle et Comportementale \\ Centre National de la Recherche Scientifique, Collège de France, 75231 Paris Cedex 05, France \\ and Laboratoire de Neuropsychologie Experimentale, Université du Québéc \\ C.P. 500, Trois Rivières, Quebec G9A-5H7, Canada
}

\begin{abstract}
The present study examined the effects in rats of different doses of ethanol $(.0-4.0 \mathrm{~g} / \mathrm{kg})$ injected ip during 3 consecutive days on subsequent voluntary consumption of the drug (Experiment 1). Ethanol treatment was found to induce a significant suppression of ethanol drinking. Five injections of naloxone $(10 \mathrm{mg} / \mathrm{kg})$ combined with ethanol $(1.75 \mathrm{~g} / \mathrm{kg})$ performed on alternate days significantly enhanced aversion (Experiment 2). The findings indicated that ethanol administered via the ip route generates both negative reinforcement (UCS) and the associated oral ethanol flavor (CS) for aversion conditioning. The implications for investigations related to obtaining an animal model of behavioral dependence toward ethanol are discussed.
\end{abstract}

The conditioned taste aversion (CTA) paradigm has been used to determine the aversive pharmacological properties of drugs and involves pairing the latter's deleterious effects (UCS) with the oral ingestion of a novel-flavored solution (CS). Ethanol administered ip produces aversive behavioral consequences that are capable of inducing taste aversion toward a saccharin solution presented orally (Eckardt, Skurdal, \& Brown, 1974; Lester, Nachman, \& Le Magnen, 1970; Marfaing-Jallat \& Le Magnen, 1979). At variance with the classical CTA method, evidence has been provided demonstrating that gustatory stimuli need not necessarily be presented orally, but can reach taste receptors and act as a CS after being administered ip. The latter route has been employed either to condition (Burešova \& Bureś, 1977; Ionescu \& Burešova, 1977) or to extinguish (Baum, Foidart, \& Lapointe, 1974) LiCl-induced aversions to the same orally presented flavor stimulus (saccharin, saccharin cyclamate). More recently, Cunningham (1978) has reported that, in rats, an ip injection of ethanol produces a taste that interacts with that of various other orally ingested flavored solutions (quinine $\mathrm{HCl}, \mathrm{NaCl}$, sucrose, and hydrochloric acid), thereby explaining the observed differential effects of ethanol on the extinction of previously conditioned aversions to these flavors.

The authors wish to thank J. L. Aucouturier for his assistance in the statistical analyses of data and ENDO Laboratories (New York) for their generous supply of naloxone $\mathrm{HCl}$. The work was supported by an IREB research grant. Address all correspondence to Dom Miceli, Laboratoire de Neurophysiologie Sensorielle et Comportementale, Collège de France, 11, place Marcelin Berthelot, 75231 Paris, Cedex 05, France.
In view of these separate findings indicating that ethanol injected ip can generate both negatively reinforcing effects (UCS) and oral taste (CS), the present study was designed to determine whether ip injections of ethanol by themselves would suffice to induce aversion to the drug, as subsequently assessed by measuring voluntary ethanol consumption using an ethanol-water preference test (Experiment 1). In a previous study, we have shown that naloxone, an opiate receptor antagonist, enhances ethanol-induced aversion toward a saccharin solution (Miceli, MarfaingJallat, \& Le Magnen, 1979). Accordingly, the effects of naloxone concurrently administered ip with ethanol on subsequent voluntary ethanol intake also were examined (Experiment 2).

\section{EXPERIMENT 1}

\section{Method}

The aim of this experiment was to determine the effects of acute ethanol administration on subsequent voluntary consumption. The study was performed on 100 adult male Wistar rats weighing $197 \pm 10 \mathrm{~g}$ (mean \pm SD). They were housed individually in wire-mesh cages in which standard laboratory chow (Pietrement) and bottles containing tap water were available ad lib. A 12/12-h dark/light cycle with light on at 8:00 a.m. was maintained throughout the experiment and the ambient temperature was kept at $20^{\circ} \mathrm{C}$. The rats were assigned randomly to five groups $(\mathrm{N}=20)$, each receiving a different dose of ethanol $(.0,1.0,2.0,3.0$, and $4.0 \mathrm{~g} / \mathrm{kg}$ ) starting at 10:00 a.m. on 3 consecutive days.

The concentration of the ethanol solution injected was $10 \%$ $(w / v)$, prepared from $95 \%$ ethanol diluted in saline. Depending on the dose, varying volumes of the standard ethanol solution were first administered ip, then followed by a second, complementary injection of saline on the opposite side of the midline. The volume of saline injected was set such that the total fluid content of both ip injections equaled $8.2 \mathrm{ml}$. Consequently, all 
doses generated by the two-injection procedure were constant with regard to both the concentration of the ethanol solution and the total volume of fluid injected. The injections were performed in a well-ventilated room separate from that housing the animals, and the abdominal sites were carefully cleaned and dried with cotton before returning the rats to their home cages. This was done in order to guard against possible environmental exposure to either ethanol odor or taste.

Ethanol preference testing was begun at 10:00 a.m. on the 4th day and lasted 4 days. During this period, two identical drinking bottles were presented, one containing $5 \%(\mathrm{v} / \mathrm{v})$ ethanol diluted in tap water, the other tap water. The positions of the bottles were alternated daily and fluid consumption was recorded.

\section{Results and Discussion}

The histograms of Figure 1 show, for the different groups, the mean quantities of ethanol solution consumed in proportion to total fluid intake. Individual intakes were cumulated over 2-day time intervals to control for position preferences. In the first time interval (Days 1-2), the control saline-treated group exhibited the highest levels of ethanol intake $(\vec{X} \pm S E$, $25.7 \% \pm 4.9 \%$ ), whereas the ethanol-treated groups drank lesser quantities: $13.4 \% \pm 4.2 \%, 11.8 \% \pm 4.0 \%$, $6.6 \% \pm 1.8 \%$, and $5.7 \% \pm 1.3 \%$ for ethanol doses of $1.0-4.0 \mathrm{~g} / \mathrm{kg}$, respectively. An increase in ethanol

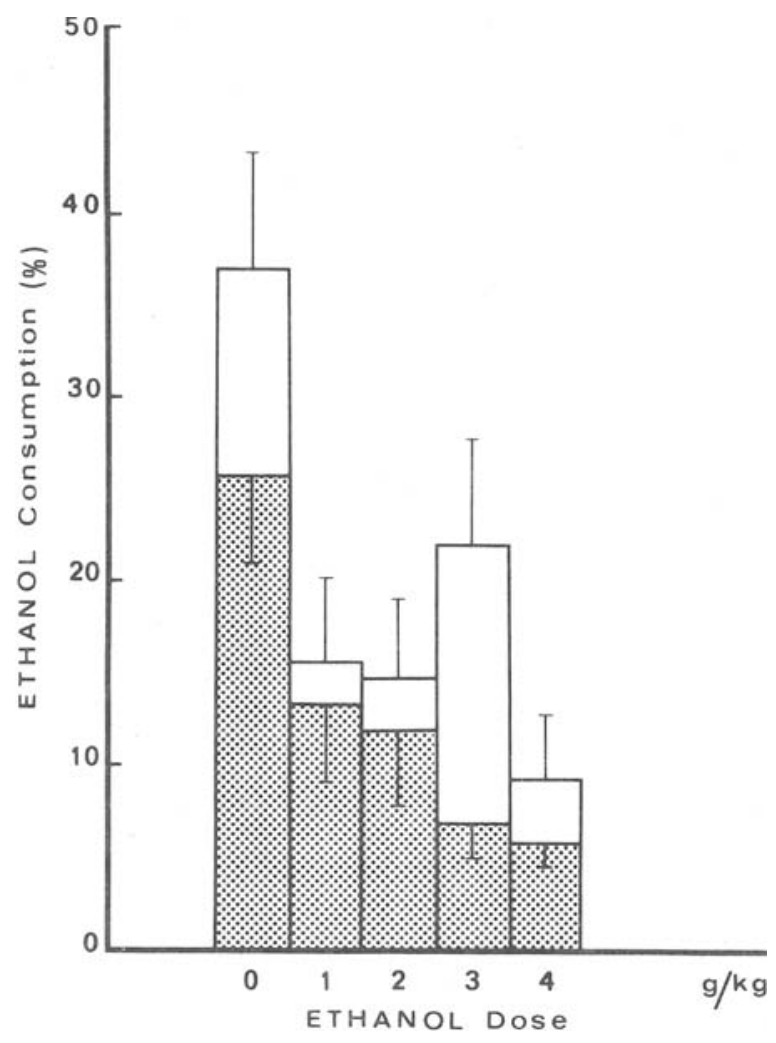

Figure 1. Experiment 1: Histograms showing, for the various groups previously treated with different doses of ethanol (.0$4.0 \mathrm{~g} / \mathrm{kg} ; \mathrm{N}=20$ ), the mean levels $( \pm \mathrm{SE})$ of ethanol consumption $(5 \% \mathrm{v} / \mathrm{v})$ in proportion to total fluid intake during the two-bottle preference test period. The values represent mean individual intakes averaged over 2-day time intervals; shaded histogram: Days 1-2; nonshaded histogram: Days 3-4. drinking was noted in all groups during the second time interval (Days 3-4). However, with the exception of a more marked relative increase in the group having received the $3.0-\mathrm{g} / \mathrm{kg}$ dose $(22.0 \% \pm 5.9 \%)$, a similar inverse relation between ethanol dose and mean ethanol consumption was observed: $37.0 \% \pm$ $6.2 \%, 15.7 \% \pm 4.7 \%, 14.7 \% \pm 4.3 \%$, and $9.2 \% \pm$ $3.6 \%$ for $.0-, 1.0-, 2.0-$, and $4.0-\mathrm{g} / \mathrm{kg}$ doses, respectively.

A two-way analysis of variance with repeated measures indicated a significant effect of dose $[F(4,190)$ $=8.58, \mathrm{p}<.001]$ and time interval $[\mathrm{F}(1,190)=6.6$, $\mathrm{p}<.001]$ but no significant dose-time interval interaction. Between-group comparisons using the Student $t$ test demonstrated significant differences between the saline control values and those of ethanol-treated groups in both time intervals, indicating that significant aversiveness was induced by prior ip treatment with ethanol. Furthermore, a test on variance of intake levels (ethanol groups 1.0-4.0 g/ kg; first time interval) showed a power function to best fit the data $(r=.99)$ and account for the ethanol doseintake relation; $y=5.96 \mathrm{x}^{-3}$ (ANOVA regression analyses: $F(1,76)=409.0, p<.001$ with nonsignificant deviation from linearity: $F(2,76)=.004)$.

\section{EXPERIMENT 2}

\section{Method}

The purpose of this experiment was to examine the acute effects of naloxone concurrently administered with ethanol on subsequent voluntary ethanol intake. The study was performed on 10 adult male Wistar rats weighing $225 \pm 2 \mathrm{~g}$ and housed under the same conditions as those described in the preceding experiment. During the ethanol-treatment (conditioning) phase, the rats were water deprived for $24 \mathrm{~h}$ and then, on alternate days, tested for periods of up to $8 \mathrm{~h}$ in the drinking apparatus for measuring behavioral tolerance (Miceli \& Le Magnen, 1979b) after ip injection of $1.75 \mathrm{~g} / \mathrm{kg}$ doses of ethanol $(4.0 \mathrm{ml}$ solution). Five animals received a second ip injection of $10 \mathrm{mg} / \mathrm{kg}$ naloxone hydrochloride (Group EN) on the opposite side of midline, whereas the other five rats (Group ES) received saline (.5 ml solution). The experimental design and the data regarding the effects of naloxone on the initial and acquired tolerance toward ethanol, using this same procedure, have been reported in a previous paper (Miceli, Marfaing-Jallat, \& LeMagnen, 1980).

At 10:00 a.m. on the day following the last day of behavioral testing, the rats were offered the two-bottle choice between solutions of ethanol and water. The ethanol concentrations used in the preference tests were $5.0 \%, 2.5 \%$, and $1.5 \%(\mathrm{v} / \mathrm{v})$ during Days 1, 2-3, and 4-11, respectively. The positions of the drinking bottles were alternated daily at 10:00 a.m. and fluid intake was recorded.

\section{Results and Discussion}

The ethanol-treatment procedure used in this study appeared to produce much stronger aversion toward ethanol than that of Experiment 1. When offered the same $5 \%$ solution on Day 1 of preference testing, EN and ES groups consumed only $4.6 \% \pm 1.1 \%$ and $6.3 \% \pm 1.1 \%$ of ethanol, respectively. A similar marked suppression of ethanol intake was observed on Days 2-3 using the $2.5 \%$ concentration (EN: 


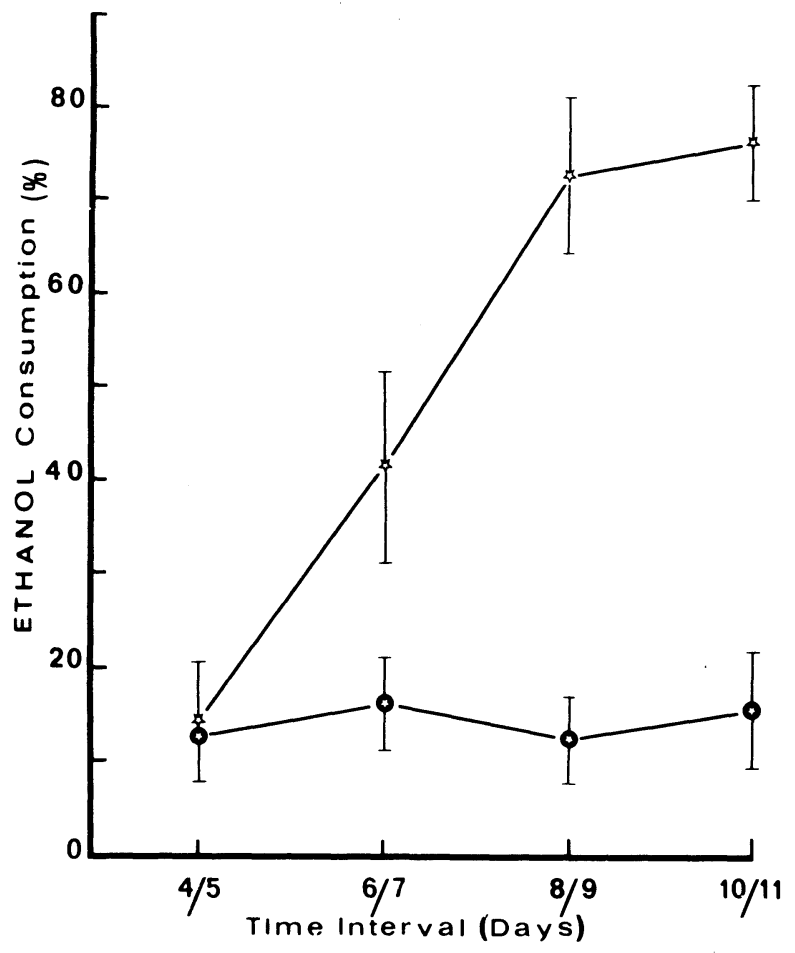

Figure 2. Experiment 2: The mean percentage intake of ethanol solution (cumulated over 2-day time intervals) recorded in the two-bottle preference test (Days 4-11 posttreatment) using the $1.5 \%(\mathrm{v} / \mathrm{v})$ ethanol solution. During the treatment period, each group received ip injections of ethanol $(1.75 \mathrm{~g} / \mathrm{kg})$ and either saline (ES, open stars) or naloxone (10 mg/kg; Group EN, enclosed stars) on 5 alternate days. Vertical lines indicate $S E$.

$4.9 \% \pm 2.4 \%$; ES: $3.0 \% \pm .7 \%$ ). Differential treatment effects became apparent only on subsequent days (4-11) when the $1.5 \%$ ethanol solution was presented. Mean daily intakes recorded during the latter period averaged over 2-day intervals are shown in Figure 2. Comparable levels of ethanol intake were noted for EN $(12.7 \% \pm 4.9 \%)$ and ES $(14.4 \% \pm 6.2 \%)$ groups on Days 4-5.

Progressive increases were observed in the ES group on Days 6-7 and 8-9 (respectively, 41.8\% $\pm 10.2 \%$ and $72.6 \% \pm 6.2 \%$ ). In contrast, the EN group continued to show a marked reduction of ethanol intake throughout the test period $(\overline{\mathrm{X}}<16.0 \%)$. A two-way ANOVA with repeated measures showed a significant difference between EN and ES groups $[F(1,32)=$ $45.5, \mathrm{p}<.001]$, effect of time interval $[\mathrm{F}(3,32)=$ $7.07, \mathrm{p}<.001$ ], and group-time interval interaction $[F(3,32)=6.85, p<.01]$. Thus, naloxone significantly enhanced the aversion toward ethanol resulting from ip administration of the drug.

\section{GENERAL DISCUSSION}

The present study demonstrated that ip injections of ethanol induced subsequent oral aversion to the drug. Because behavioral tolerance with the drinking test could not be assessed without administering a challenge dose of ethanol, there were no saline-treated controls in Experiment 2. Nevertheless, the smaller quantities of ethanol consumed when the rats were offered either the same $5 \%$ or the $2.5 \%$ concentrations of ethanol indicated that these animals experienced much stronger aversion than those in Experiment 1. For corresponding time intervals after ethanol treatment, the mean intake levels in Experiment 2 (Group ES) were lower than in Experiment 1, even including those groups injected with higher doses of ethanol $(2.0,3.0$, and $4.0 \mathrm{~g} / \mathrm{kg}$; respectively, $\mathrm{U}(5,20)=43.5,35.5$, and $36.0 ; \mathrm{p}<.02$, MannWhitney $U$ test). These differences in the degree of aversion produced may be attributed to several experimental variables, such as the number of conditioning trials ( 3 vs. 5 ), the treatment schedule (consecutive vs. alternate days), and the complexity of the experimental design. In the first experiment, animals were simply injected and then returned to their home cages, whereas, in the second, the rats received their injections after $24 \mathrm{~h}$ of water deprivation and then underwent behavioral testing while intoxicated. Further studies regarding the time course of induction of aversion are required in order to determine more precisely the relevance of these different variables, particularly the parameters of ethanol treatment (dose, periodicity, duration).

Significant aversiveness was obtained with three conditioning injections of a $1.0-\mathrm{g} / \mathrm{kg}$ dose of ethanol (Experiment 1). The degrees of intoxication produced by the various doses tested $(1.0-4.0 \mathrm{~g} / \mathrm{kg})$ ranged from mild to severe, 3.0 and $4.0 \mathrm{~g} / \mathrm{kg}$ being anesthetic doses. Although the ethanol dose-aversion relation was found to be linear (first time interval) and appeared to represent a power function, the slope of the curve $(-.3)$ indicated relatively small changes in the level of aversion with increasing ethanol dose. One possible explanation is linked to ethanol's anesthetic effects in that, at the higher doses, the conditioning process may have been temporarily blocked until the high blood-alcohol concentrations returned to lower levels. Anesthetic blockade of the CS-UCS association has been reported in an investigation using $\mathrm{LiCl}$ poisoning to induce saccharin aversion when the saccharin CS was also administered via the ip route (Burešova \& Bureš, 1977).

In the present study, naloxone was shown to enhance ethanol aversion, and this is in accordance with the finding that the narcotic antagonist enhances ethanol-induced taste aversion toward a saccharin solution presented orally (Miceli et al., 1979). This effect might be due to naloxone's nonspecific enhancement of the affective response to nociceptive stimuli (Amir \& Amit, 1978; Bass, Friedman, \& Lester, 1978; Grevert \& Goldstein, 1977; Jacob \& Ramabadran, 
1978), as it has been found to alter neither initial nor acquired tolerance toward ethanol (Miceli et al., 1980).

Altogether, the results indicated that ethanol administered via the ip route generated both a negative reinforcement (UCS) and the associated oral ethanol stimulus (CS) for inducing taste aversion. This finding is compatible with previous data showing that an ip injection of ethanol can be employed as a UCS in establishing a saccharin taste aversion (Eckardt et al., 1974; Lester et al., 1970; Marfaing-Jallat \& Le Magnen, 1979) and, in addition, produces an ethanol taste as assessed by its effects on the extinction of taste aversion to various other flavored oral stimuli (Cunningham, 1978). Moreover, the latter is consistent with the notion that gustatory (Bradley \& Mistretta, 1971) or olfactory stimuli injected parenterally can stimulate their respective receptors via salivary secretion and pulmonary excretion into the expired air.

The present findings have implications for studies related to obtaining models of behavioral dependence toward ethanol in animals. Such dependence, defined as a persistent high level of voluntary ethanol intake given an ethanol-water choice and following prolonged periods of forced oral ingestion or inhalation methods, has not been observed in rats and mice. Bypassing the oral sensory apparatus by chronically administering ethanol via the ip, iv, or intragastric routes has also failed to produce the phenomenon. A contributory factor, regardless of the route of chronic administration and in spite of the fact that these various treatments produce physical dependence and increased tolerance (Goldstein \& Pal, 1971; Majchrowicz \& Hunt, 1976; Miceli \& Le Magnen, 1979a), may be that an ethanol flavor aversion is induced during the course of the ethanol treatment. High and persistent blood-alcohol levels would provide a continuous CS-UCS association and the conditions for consolidating aversion.

It is conceivable that the process involved in conditioning taste aversion toward ethanol in the present study may be extended to a variety of other endogenous or exogenous flavored and odorous stimuli that produce negative behavioral consequences. Similarly, the parenteral conditioning model might be applicable to the induction of taste preferences when the CS agents are positively reinforcing.

\section{REFERENCES}

AMIR, S., \& AMIT, Z. Endogenous opioid ligands may mediate stress-induced changes in the affective properties of pain related behavior in rats. Life Sciences, 1978, 23, 1143-1152.

Bass, M. B., Friedman, H. J., \& Lester, D. Antagonism of naloxone hyperalgesia by ethanol. Life Sciences, 1978, 22, 1939-1946.

Baum, M., Foidart, D. S., \& LaPointe, A. Rapid extinction of a conditioned taste aversion following unreinforced intraperitoneal injection of the fluid CS. Physiology \& Behavior, 1974, 12, 871-873.

Bradley, R. M., \& Mistretta, C. M. Intravascular taste in rats as demonstrated by conditioned aversion to sodium saccharin. Journal of Comparative and Physiological Psychology, 1971, 2, 186-189.

BurEŠOVA, O., \& BurEš, J. The effect of anesthesia on acquisition and extinction of conditioned taste aversion. Behavioral Biology, 1977, 20, 41-50.

CunNingham, C. L. Alcohol interacts with flavor during extinction of conditioned taste aversion. Physiological Psychology, 1978, 6, 510-516.

ECKardt, M. J., Skurdal, A. J., \& Brown, J. S. Conditioned taste aversion produced by low doses of alcohol. Physiological Psychology, 1974, 2, 89-92.

Goldstein, D. B., \& PAL, N. Alcohol dependence produced in mice by inhalation of ethanol: Grading the withdrawal reaction. Science, 1971, 172, 288-290.

Grevert, P., \& Goldstein, A. Some effects of naloxone on behavior in the mouse. Psychopharmacology, 1977, 53, 111-113.

IONESCU, E., \& BUREŠOVA, O. Effects of hypothermia on the acquisition of conditioned taste aversion in rats. Journal of Comparative and Physiological Psychology, 1977, 91, 1297-1307.

JACOB, J. J., \& RAMABADRAN, K. Enhancement of nociceptive reaction by opioid antagonists in mice. Journal of Pharmacology, 1978, 64, 91-98.

Lester, D., Nachman, M., \& Le Magnen, J. Aversive conditioning by ethanol in the rat. Quarterly Journal of Studies on Alcohol, 1970, 31, 578-586.

MAJChrowicz, E., \& HUNT, W. A. Ethanol tolerance and physical dependence in rats. Psychopharmacology, 1976, 50, 107-112.

Marfaing-Jallat, P., \& Le Magnen, J. Ethanol-induced taste aversion in ethanol-dependent and normal rats. Behavioral and Neural Biology, 1979, 26, 106-114.

Miceli, D., \& LE MAGnen, J. Relations between metabolic and nervous tolerance towards ethanol in naive and chronically intoxicated rats. Pharmacology, Biochemistry \& Behavior, 1979, 10, 329-334. (a)

Miceli, D., \& Le Magnen, J. A simple drinking test for measuring the effects of ethanol on the C.N.S. Psychopharmacology, 1979, 66, 257-261. (b)

Miceli, D., Marfaing-Jallat, P., \& Le Magnen, J. Non-specific enhancement of ethanol-induced taste aversion by naloxone. Pharmacology, Biochemistry \& Behavior, 1979, 11, 391-394.

Miceli, D., Marfaing-Jallat, P., \& Le Magnen, J. Failure of naloxone to affect initial and acquired tolerance towards ethanol in rats. European Journal of Pharmacology, 1980, 63, 327-333.

(Received for publication October 23, 1979; revision accepted May 19, 1980.) 